\title{
Long-term Glioblastoma Multiforme Survivors: a Population-based Study
}

\author{
J.N. Scott, N.B. Rewcastle, P.M.A. Brasher, D. Fulton, N.A. Hagen, \\ J. A. MacKinnon, G. Sutherland, J.G. Cairncross and P. Forsyth
}

\begin{abstract}
Background: Long-term glioblastoma multiforme survivors (LTGBMS) are uncommon. The frequency which these occur in an unselected population and factors which produce these unusually long survivors are unknown. Objectives: To determine in a population-based study 1) the frequency of LTGBMS in a population and 2) identify which patient, treatment or tumor characteristics would predict which glioblastoma (GBM) patient would become a LTGBMS. Methods: The Alberta Cancer Registry was used to identify all patients diagnosed with GBM in southern Alberta between 1/1/75 - 12/31/91. Patient charts were reviewed and histology re-examined by a blinded neuropathologist. LTGBMS were defined as GBM patients surviving $\geq 3$ years after diagnosis. Each LTGBMS was compared to three age-, gender-, and year of diagnosis-matched controls to compare patient, treatment, and tumor factors to GBM patients without long-term survival. Results: There were 279 GBMs diagnosed in the study period. Five (1.8\%) survived $\geq$ three years (range, $3.2-15.8$ years). Seven additional long-term survivors, who carried a diagnosis of GBM, were excluded after neuropathologic review; the most common revised diagnosis was malignant oligodendroglioma. LTGBMS (avg. age $=45$ years) were significantly younger when compared to all GBM patients (avg. age $=59$ years, $p=0.0001$ ) diagnosed in the study period. LTGBMS had a higher KPS at diagnosis $(p=0.001$ ) compared to controls. Tumors from LTGBMS tended to have fewer mitoses and a lower Ki-67 cellular proliferative index compared to controls. Radiation-induced dementia was common and disabling in LTGBMS. Conclusions: These data highlight the dismal prognosis for GBM patients who have both a short median survival and very small chance $(1.8 \%)$ of long-term survival. The LTGBMS were younger, had a higher performance status, and their tumors tended to proliferate less rapidly than control GBM patients. When long-term survival does occur it is often accompanied by severe treatment-induced dementia.
\end{abstract}

RÉSUMÉ: Survie à long terme des cas de glioblastome multiforme: une étude de population. Introduction: La survie à long terme est rare chez les cas de glioblastome multiforme (GM). La fréquence de ces cas dans une population non sélectionnée et les facteurs qui contribuent à une survie prolongée sont inconnus. Objectifs: Le but de cette étude sur le GM était de déterminer 1) la fréquence des survivants à long terme dans une population et 2) d'identifier quelles caractéristiques des patients, du traitement ou de la tumeur prédisent quel patient atteint de GM survivra à long terme. Méthodes: Nous avons utilisé le Registre du cancer de l'Alberta pour identifier tous les patients du sud de l'Alberta qui ont reçu un diagnostic de GM entre le $1 / 1 / 75$ et le 31/12/91. Les dossiers des patients ont été révisés et les coupes anatomopathologiques ont été examinées à l'insu par un neuropathologiste. Les survivants à long terme étaient définis comme des cas de GM survivant $\geq 3$ ans après le diagnostic. Chacun de ces cas était comparé à 3 contrôles appariés quant à l'âge, au sexe et à l'année du diagnostic pour comparer le patient ayant eu une survie prolongée, le traitement et les facteurs tumoraux de ces patients, à des cas de GM n'ayant pas survécu à long terme. Résultats: Il y a eu 279 diagnostics de GM posés pendant la période de l'étude. Cinq (1.8\%) ont survécu $\leq 3$ ans (écart de 3.2 à 15.8 ans). Sept autres cas de GM ayant eu une survie à long terme ont été exclus après révision neuropathologique; le diagnostic révisé était le plus souvent celui d'oligodendrogliome malin. Les survivants à long terme (âge moyen 45 ans) étaient significativement plus jeunes comparés à tous les patients atteints de GM (âge moyen 59 ans, $\mathrm{p}=0.0001$ ) diagnostiqués pendant la durée de l'étude. Ils avaient un score KPS (Karnofsky performance status) plus élevé au moment du diagnostic par rapport aux contrôles $(p=0.001)$. Les tumeurs des survivants à long terine avaient en général moins de mitoses et un indice de prolifération cellulaire Ki-67 plus bas que les contrôles. La démence induite par l'irradiation était fréquente et invalidante chez les survivants à long terme. Conclusions: Ces données soulignent le pronostic sombre chez les patients atteints de GM qui ont en général une survie médiane courte et une faible chance (1.8\%) de survie à long terme. Les survivants à long terme étaient plus jeunes, avaient un niveau de performance plus élevé et leur tumeur proliférait en général plus lentement par rapport aux patients contrôles. La survie à long terme est rare et souvent accompagnée d'une démence induite par le traitement.

Can. J. Neurol. Sci. 1998; 25: 197-201

From the Departments of Clinical Neurosciences and Pediatrics. The University of Calgary and Department of Medicine, Foothills Hospital and Tom Baker Cancer Centre (TBCC), Calgary, (J.N.S., N.A.H., G.S., P.F.); Department of Pathology and Clinical Neurosciences, The University of Calgary and Department of Medicine, Foothills Hospital, Calgary, (N.B.R.); Department of Epidemiology, Prevention and Screening. Alberta Cancer Board and Community Health Sciences, The University of Calgary, Calgary, (P.M.A.B.); Department of Radiation Oncology, Cross Cancer Institute (CCI) and Department of Medicine/Neurology, University of Alberta, Edmonton, (D.F.); Department of Radiation Oncology, Tom Baker Cancer Centre (TBCC), The University of Calgary, Calgary, (J.A.M.); Departments of Clinical Neurological Sciences and Oncology,
University of Western Ontario and London Regional Cancer Centre. London. Ontario, (J.G.C.).

RECEIVED NOVEMBER 6, 1997. ACCEPTED IN FINAL FORM FEBRUARY 10, 1998 Presented in abstract form at the 1996 American Academy of Neurology Meeting. Scott, J.N., Rewcastle, N.B., Brasher. P., MacKinnon, J., Hagen, N., Cairncross, J.G., Forsyth. P. Which GBM patient will be a longterm GBM survivor (LTGBMS)? A case-controlled population-based study in southern Alberta. Neurology 1996; 40(2): A181.

Reprint requests to: P. Forsyth, Department of Medicine, Tom Baker Cancer Centre, $1331-29$ Street N.W., Calgary, Alberta, Canada T2N 4N2 
The prognosis for patients with glioblastoma multiforme (GBM) is very poor; the median survival with the best available treatment is only twelve months and the survival rate has changed little in the past twenty years. ${ }^{1,2}$ We recently encountered a GBM patient who was alive fifteen years after diagnosis and recognized this as highly unusual. We were curious as to how commonly GBM patients survived for a prolonged time in an unselected population of brain tumor patients and sought to identify factors which might predict long survival, as well as to determine if a histologic re-examination of putative long-term GBM survivors (LTGBMS) would uncover glioma subtypes ${ }^{3-5}$ which masqueraded as GBMs.

LTGBMS have been described by others ${ }^{6-14}$ as uncommon, occurring in 1-17\% of GBM patients. The factors found by these studies that were associated with long-term survival were unsurprising and included the use of multimodality therapy, young age and a high performance status at diagnosis. $6,7,10-13$ There are two limitations of these reports. First, only one of these ${ }^{9}$ was population-based. The others were institutional series which contained highly selected patients and therefore may not reflect the true incidence of LTGBMS in the general population of brain tumor patients. Second, previous comparisons between LTGBMS and their shorter surviving counterparts have been uncontrolled for known prognostic factors; this might mask other previously identified prognostic characteristics specific for long-term survival. To address these two issues, we performed a population-based, case-controlled study and compared each identified LTGBMS with three age-, gender, and year of diagnosis-matched control GBM patients.

This study was designed to determine 1) the frequency of LTGBMS in a population, and 2) to identify which patient, treatment or tumor characteristics predicted which GBM patient became a LTGBMS. Information regarding long-term treatment effects and revised histologic diagnoses of putative LTGBMS was also recorded.

\section{Patients and Methods}

\section{Patient Selection Criteria}

The Alberta Cancer Registry is a population-based cancer registry for the Province of Alberta which was established in 1941 by Provincial Legislature and is supported and funded by the Ministry of Health. All hospitals, pathologic laboratories, radiographic facilities and cancer treatment centres participate and all patients with a clinical, radiographic or histologic diagnosis of cancer (including those diagnosed only at autopsy) are to be registered by statute.

We identified all southern Alberta residents (population in 1996 of 1.2 million) diagnosed with GBM between January 1, 1975 and December 31, 1991 as recorded in the Cancer Registry. $\dagger$ Each glioma patient's chart and pathology report was reviewed to ensure concordance with the Cancer Registry data. For the purposes of this study, a long-term survivor was defined as a patient with a GBM who lived at least 36 months after the time of tissue diagnosis. Patients in whom the diagnosis of GBM was not confirmed on histological review, or whose length of survival could not be determined, were excluded. Each LTGBMS was compared to three age-, gender-, and year of diagnosismatched controls. A retrospective chart review of all GBM patients was used to define clinical and treatment factors and subsequent clinical outcomes. Long-term survivors or their relatives, when possible, were contacted to obtain information regarding current cognitive function and performance status. This study received ethical approval by our Institutional Review Board.

\section{Histopathology}

All LTGBMS tumor specimens were reviewed by a single neuropathologist (NBR) in a blinded fashion to confirm the diagnosis and assess identified histologic features. The accepted histologic criteria for a GBM included a malignant astrocytic neoplasm with the presence of vascular and endothelial proliferation, as well as necrosis. All paraffin-embedded hematoxylin and eosin (H\&E) stained sections of tissue submitted to the laboratory were used. Several features were graded as either present or absent (necrosis, increased vascularity, and lymphocytic infiltrates), while others were qualitatively graded (endothelial proliferation, nuclear pleomorphism and size). Mitoses were counted in 5 contiguous microscope fields examined at $400 \mathrm{x}$ magnification $\left(0.2 \mathrm{~mm}^{2} / 400 \mathrm{x}\right.$ field, for a total of $\left.1.0 \mathrm{~mm}^{2}\right)$ starting in the area of the greatest pleomorphism and cellularity. Ki-67 immunostaining was performed according to established protocols (Immunotech, Marseille, France). The area with the highest number of labeled cells was identified. In this area, the percentage of $\mathrm{Ki}$-67-positive nuclei (called the labelling index) was determined by counting 1,000 nuclei in contiguous microscopic fields at 400 $\mathrm{x}$ magnification. Cells recognizable as pertaining to blood vessels (e.g., endothelial cells and pericytes) were not counted. A nucleus was considered positive if it demonstrated either a diffuse or strong punctate distribution of reaction product.

\section{Stastistical Analysis}

Statistical analyses were carried out according to the Statistical Analysis System (SAS Institute Inc., SAS/STAT User's Guide, Version 6, Fourth Edition, Cary, NC). Univariate conditional logistic regression was used to examine the influence of prognostic variables. In one case, (Ki-67) near perfect prediction was encountered (that is in each matched set the value for Ki-67 in the LTGBMS was less than its control cases) and so unconditional logistic regression was used.

\section{RESULTS}

We identified 286 patients who were residents of southern Alberta diagnosed with GBM over the 27 year study period. Of these 286 GBM patients, only $5(1.8 \%)$ were confirmed LTGBMS after histological review. Their clinical characteristics are summarized in Table 1 . Two were women and three were men; the mean age was 45 years (range, $32-58$ yrs). The LTGBMS were significantly younger when compared to all GBM patients diagnosed in the study period (average age, 59 years) $(p=0.0001 ;$ t-test $)$.

$\dagger$ [International Classification of Diseases for Oncology topography codes C71.- (Brain) and multiple morphology codes designed to capture all GBMs or gliosarcomas $(94-403,413,423)$ and all gliomas $(93-803,823,923: 94-001,003,013,113,203,513)$ with a grade 4 and an unknown or missing grade.] 
Table 1: Clinical characteristics of LTGBMS ${ }^{1}$ in southern Alberta.

\begin{tabular}{|c|c|c|c|c|c|c|}
\hline Age / Gender & $\mathbf{K P S}^{2}$ & $\begin{array}{l}\text { Presenting } \\
\text { Symptoms }^{3}\end{array}$ & $\begin{array}{l}\text { Duration of } \\
\text { Symptoms (wks) }\end{array}$ & Status 5 & Dementia $^{6}$ & Survival (yrs) ${ }^{7}$ \\
\hline $43 /$ female & 90 & $\mathrm{Sz}$ & 8 & $A ; N E D$ & +++ & 15.8 \\
\hline $58 /$ female & 90 & $\mathrm{Hp}, \mathrm{V}$ & 104 & $\mathrm{D}$ & + & 6.8 \\
\hline $32 /$ male & 90 & $\mathrm{Sz}$ & 12 & D & N/A & 4.6 \\
\hline $46 /$ male & 90 & MSC & 32 & $\mathrm{~A} ; \mathrm{PD}$ & +++ & 5.8 \\
\hline
\end{tabular}

'LTGBMS = Long-term GBM survivor; GBM patients surviving $\geq$ three years after tissue diagnosis.

${ }^{2} \mathrm{KPS}=$ Karnofsky Performance Status at presentation and diagnosis $(100=$ normal function and $0=$ dead $)$.

${ }^{3} \mathrm{Sz}=$ seizure; $\mathrm{V}=$ visual symptoms; $\mathrm{MSC}=$ mental status change; $\mathrm{Hp}=$ hemiparesis.

${ }^{4}$ Duration of symptoms from symptom onset to diagnosis.

${ }^{5}$ Patient status at follow-up: NED = no evident disease; $\mathrm{PD}=$ progressive disease.

${ }^{6}$ Suspected radiation-induced dementia; graded from + (mild) to +++ (severe).

${ }^{7}$ Length of survival from diagnosis.

$\mathrm{N} / \mathrm{A}=$ unable to assess cognitive status.

Table 2: Clinical comparisons between LTGBMS and control GBM patients.

\begin{tabular}{|c|c|c|c|}
\hline Factor & $\begin{array}{l}\text { LTGBMS' }^{1} \\
(\mathrm{~N}=5)\end{array}$ & $\begin{array}{l}\text { Controls }^{1} \\
(\mathrm{~N}=15)\end{array}$ & p Value ${ }^{2}$ \\
\hline $\mathrm{KPS}^{3} \geq 90$ & $5 / 5$ & $3 / 15$ & $p=0.001$ \\
\hline \multicolumn{4}{|l|}{ Presenting Symptoms } \\
\hline seizure & 3 & 2 & \\
\hline hemiparesis & 1 & 8 & \\
\hline headache & 0 & 10 & \\
\hline mental status change & 1 & 1 & \\
\hline personality change & 1 & 1 & \\
\hline visual symptoms & 2 & 2 & \\
\hline Symptom Duration ${ }^{4}$ (wks) & $52.0(8-104)$ & $7.2(1-52)$ & \\
\hline Subtotal surgical resection & 5 & 15 & \\
\hline \multicolumn{4}{|l|}{ Radiotherapy } \\
\hline$<6000 \mathrm{cGy} y^{5}$ & 2 & 6 & \\
\hline$\geq 6000 \mathrm{cGy}$ & 3 & 8 & \\
\hline Chemotherapy $^{6}$ & 1 & 0 & \\
\hline
\end{tabular}

1Proportion of LTGBMS or controls having the respective factor (a single patient may present with $\geq 1$ symptom).

${ }^{2}$ Chi-square from conditional logistic regression; only $\mathrm{p}$ values $<0.05$ are reported.

${ }^{3} \mathrm{KPS}=$ Karnofsky performance status at diagnosis to measure functional status $(100=$ normal function and $0=$ dead $)$.

${ }^{4}$ Symptom duration before diagnosis.

${ }^{5}$ Total radiotherapy dose $<$ or $\geq 6000 \mathrm{cGy}$.

${ }^{6}$ Chemotherapy: one LTGBMS received CCNU and one control patient received Misonidazole.

\section{Clinical Comparisons Between LTGBMS and Control GBM Patients}

The LTGBMS are compared to their respective control GBM patients in Table 2. All LTGBMS and control patients under- went a subtotal surgical debulking of their tumors and none had a gross total resection. Post-operatively, all patients received external beam radiation therapy with the exception of a single control patient who died several days after the tissue diagnosis was made. Four LTGBMS received whole brain plus boost to involved field, while the fifth LTGBMS received local plus boost therapy. All control patients received whole brain plus boost therapy. The total radiation therapy dose used was $6600 \pm$ $310 \mathrm{cGy}$ (LTGBMS $6750 \pm 520$ ) and controls $6540 \pm 380 \mathrm{cGy}$ ). Only a single LTGBMS, and no control patients, received adjuvant chemotherapy at the time of documented tumor recurrence. Three LTGBMS and a single control patient had a re-operation and further debulking at tumor recurrence.

LTGBMS were significantly more likely to have a higher level of function as determined by the Karnofsky Performance Status (KPS; all were $>90)$ at diagnosis than their controls $(p=$ 0.001 ); only three $(20 \%)$ control patients had a KPS of 90 and most were disabled at diagnosis. There was a trend for the symptom duration before diagnosis to be longer in the LTGBMS (average 52 weeks; range 8-104) than controls (average 7.2 weeks; range 1-52), although this did not reach statistical significance $(p=0.098)$. Other clinical factors were similar between the two groups. All LTGBMS for whom sufficient follow-up information was available were demented.

\section{Histologic Comparisons Between LTGBMS and Control GBM Patients}

These comparisons are summarized in Table 3. The tumors from the long-term survivors tended to have fewer mitotic figures $(p=$ $0.122)$ and a lower Ki-67 labelling index $(p=0.094)$ compared to controls, although these did not reach statistical significance. Other pathologic factors were similar between the two groups.

\section{Long-Term Survivors With a Revised Histological Diagnosis}

There were seven patients $(2.4 \%)$ who survived more than three years whose histologic diagnosis was revised during our review (Table 4). These did not meet the criteria of GBM and were excluded from our analysis. As expected, the largest excluded group of tumors were either malignant oligo- 
Table 3: Histologic comparisons between LTGBMS and control GBM patients.

\begin{tabular}{|c|c|c|c|}
\hline Factor & $\begin{array}{l}\text { LTGBMS } \\
(\mathbf{N}=\mathbf{5})\end{array}$ & $\begin{array}{l}\text { Controls } \\
(\mathbf{N}=5)\end{array}$ & p Value ${ }^{1}$ \\
\hline \multicolumn{4}{|c|}{ Number of Mitotic Figures ${ }^{2}$} \\
\hline Mean \pm SEM & $4.2 \pm 0.86$ & $13.2 \pm 3.51$ & 0.122 \\
\hline Range & $2-7$ & $1-52$ & \\
\hline \multicolumn{4}{|c|}{ Ki-67-Labelling Index ${ }^{3}$} \\
\hline Mean \pm SEM & $8.78 \pm 1.78$ & $19.1 \pm 1.37$ & $0.094^{*}$ \\
\hline Not Significant: & $\begin{array}{l}\text { - presence of endotheli } \\
\text { cytic infiltrates } \\
\text { - nuclear size or pleor }\end{array}$ & $\begin{array}{l}\text { I proliferation } \\
\text { orphism }\end{array}$ & or lympho- \\
\hline
\end{tabular}

'Chi-square from conditional (or *unconditional) logistic regression. ${ }^{2}$ Mitotic figures per $1.0 \mathrm{~mm}^{2}$ as determined by measuring 5 fields $\mathrm{x}$ $\left(0.2 \mathrm{~mm}^{2} / 400 \times\right.$ Mag field $)$.

${ }^{3}$ Labeling index or percentage of Ki-67-labelled nuclei.

SEM = standard error of the mean.

Table 4: Long-Term Survivors With Revised Histological Diagnosis. ${ }^{1}$

Malignant oligodendroglioma (2)

Malignant mixed oligodendroglioma-astrocytoma (2)

Malignant astrocytoma (1)

Medulloblastoma (1)

Sample not diagnostic of neoplasm (1)

I Seven of twelve long-term surviving patients (survived $\geq$ three years) whose original diagnosis of GBM was changed on pathological review.

dendrogliomas or malignant mixed gliomas which both contained necrosis. We did not encounter other specific glioma subtypes (e.g., pilocytic astrocytoma ${ }^{15}$ ) on our pathological review which could have initially masquaraded as GBMs.

\section{Discussion}

This study confirms that long-term survival is possible in GBM patients but rare; only $1.8 \%$ of patients in our population survived more than three years. This emphasizes the dismal prognosis for conventionally treated patients with GBMs who have both a short median survival of $8-12$ months $s^{1.2}$ and a very small chance of long-term survival.

The two most powerful prognostic factors in GBM patients are age and performance status. The present study and others ${ }^{10-}$ 13.16 confirm this observation in LTGBMS. Our LTGBMS were younger than most GBMs and each had a KPS of 90 at diagnosis which was significantly higher than the shorter-surviving GBM patients. Other favorable prognostic factors, such as a long duration of symptoms before diagnosis and the presence of seizures, have been reported less consistently. However, the LTGBMS in our series tended to have a longer symptom duration before diagnosis and most LTGBMS presented following a seizure. Other reports describing treatment factors which are associated with long-term survival include multimodality therapy consisting of gross total resection, irradiation, and adjuvant chemotherapy. We did not find differences in treatment between the two groups and this reflects the uniform care given in our centrally coordinated cancer care system. However, this uniformity of treatment prevented us from determining whether, for example, there was a dose-response relationship for radiotherapy or if a complete surgical resection was superior to biopsy.

We observed two potential prognostic factors amongst the tumor characteristics studied which might predict long survival, although they did not reach the traditional levels of statistical significance. Tumors from LTGBMS tended to have both fewer mitoses and a lower proliferative index. High mitotic counts were almost always associated with a high proliferative index with the exception of three control patients whose tumors displayed few mitoses but had clearly elevated proliferative indices. We initially speculated that LTGBMS may have more lymphocytic infiltrates, reflecting a better host response, but this was uncommon in both the study and control groups. We confined our study to histologic descriptions; others have examined molecular phenotype ${ }^{13,17-19}$ but have not found consistent associations between expression of p53 or epidermal growth factor receptor with long-term survival.

Our study has several limitations. First, few of our patients received adjuvant chemotherapy which reflected institutional practice patterns during the study period. Since adjuvant chemotherapy increases the proportion of patients surviving to $\geq$ 18 months ${ }^{20,21}$ the incidence of LTGBMS we observed may not apply to populations where such therapy is routinely given. A second limitation of our study is conceptual. We initially believed that LTGBMS were biologically "different" from their shorter-surviving counterparts and this formed the premise of our study. However, this assumption may not be valid since all but one LTGBMS either died or had progressive disease. "LTGBMS" may be only a statistical effect where these patients simply represent the extreme tail of a distribution and are not categorically different. But one of our very long surviving patients (> 15 years after diagnosis) and other patients reported elsewhere, suggested to us that LTGBMS may be a distinct but rare entity. A third limitation is the small number of LTGBMS we observed. This means that only very large differences between the groups would be statistically significant.

Progressive cognitive deterioration was observed in three of our five LTGBMS who displayed severe dementia in the absence of documented tumor recurrence. All five had received whole-brain irradiation which caused their dementia. It is distressing that dementia and a loss of independence may be the usual outcomes for LTGBMS and malignant glioma survivors ${ }^{22}$ when aggressive therapy successfully controls the tumor. This may be less common now that local radiation therapy has replaced whole-brain treatment.

One important implication of this study is that a re-evaluation of the original histology be considered when a GBM patient with a long survival is encountered. Most of our putative GBM patients with long-term survival are initially misdiagnosed; others report similar findings..$^{9.23}$ This is not unexpected as several tumors may superficially resemble a GBM histologically $5,13,15$ and, now that malignant oligodendrogliomas have been recognized as being highly chemo-sensitive, ${ }^{24}$ gliomas with necrosis are more carefully examined and not necessarily called GBM. The most common revised diagnosis in our patients and others 5 was malignant oligodendroglioma (pure or mixed); others have found more indolently growing tumors such as pleomorphic xanthoastrocytoma ${ }^{13}$ in long term survivors. The confusion 
between a GBM and a malignant oligodendroglioma may account for some unusual patients in the literature who have long survivals and good responses to adjuvant chemotherapy. ${ }^{5}$

In conclusion, this population-based study of GBM patients shows that long-term survival is rare and highlights the clinical challenge of this disease. Young age and a high pre-operative KPS favor long-term survival but these were non-specific factors and do not assist the clinician in developing a management strategy for an individual patient. In our population, we were not able to identify other clinical features or therapeutic interventions which were associated with long-term survival. Pathological features which tended to be found in long-term survivors were a low mitotic count and proliferative index. Having assembled this group of patients we are extending our clinical study to a larger population where adjuvant chemotherapy is more commonly used.

\section{ACKNOWLEDGEMENTS}

We thank our patients and their families for participating in this study and Ms. Jackie Appleton and Tom Snodgrass for their expert technical and supportive assistance. This study was supported in part by an infrastructural grant from the Alberta Cancer Board.

\section{REFERENCES}

1. Fine HA. The basis for current treatment recommendations for malignant gliomas. J Neuro-Oncol 1994; 20: 111-120.

2. Forsyth PA, Cairncross JG. Treatment of malignant glioma in adults. Curr Opin Neurol 1995; 8: 414-418.

3. Kepes JJ, Rubinstein LJ, Eng LF. Pleomorphic xanthoastrocytoma: a distinctive meningocerebral glioma of young subjects with relatively favorable prognosis. Cancer $1979 ; 44: 1839-1852$.

4. Daumas-Duport C, Scheithauer B, O'Fallon J, Kelly P. Grading of astrocytomas: a simple and reproducible method. Cancer 1988; 62: 2152-2165.

5. Balmaceda C, Goldman J, Fetell MR. Long-term survival in malignant astrocytomas re-evaluated: are they really oligodendrogliomas? Neurology 1996; 46(2): A451 (Abstr).

6. Elvidge AR, Barone BM. Long-term postoperative survival in two cases of glioblastoma multiforme. J Neurosurg 1965; 22: 382-386.

7. Müller $H$, Brock $M$, Ernst $H$. Long-term survival and recurrence-free interval in combined surgical, radio- and chemotherapy of malignant brain gliomas. Clin Neurol Neurosurg 1985; 87(3): 167-171.

8. Imperato JP, Paleologos NA, Vick NA. Effects of treatment on long-term survivors with malignant astrocytomas. Ann Neurol 1990; $28: 818-822$.
9. Ullén H, Mattsson B, Collins VP. Long-term survival after malignant glioma: a clinical and histopathological study on the accuracy of the diagnosis in a population-based cancer registry. Acta Oncol 1990; 29: 875-878.

10. Vertosick FT, Selker RG. Long-term survival after the diagnosis of malignant glioma: a series of 22 patients surviving more than 4 years after diagnosis. Surg Neurol 1992; 38: 359-363.

11. Chandler KL, Prados MD, Malec M, Wilson CB. Long-term survival in patients with glioblastoma multiforme. Neurosurgery 1993; 32(5): 716-720.

12. Salcman M, Scholtz H, Kaplan RS, Kulik S. Long-term survival in patients with malignant astrocytoma. Neurosurgery 1994; 34(2): 213-220.

13. Morita M, Rosenblum MK, Bilsky MH, Fraser RAR, Rosenfeld MR. Long-term survivors of glioblastoma multiforme: clinical and molecular characteristics. J Neuro-Oncol 1996; 27: 259-266.

14. Olivera C, Bartley M. Ferrall S, Phuphanich S. Long-term malignant glioma survivors over ten years: prognostic factors. Proceedings of ASCO 1997; 16: 407a (Abstr).

15. Forsyth PA, Shaw E, Scheithauer B, Layton D, O'Fallon J. 51 Cases of supratentorial pilocytic astrocytoma: a clinicopathologic, prognostic, and flow-cytometric study. Cancer 1993; 72: 1335-1342.

16. Byar DP, Green SB, Strike TA, et al. Prognostic factors for malignant glioma. In: Walker MD, ed. Oncology of the Nervous System. Boston: Marinus Nijhoff, 1983: 379-395.

17. Jaros E, Perry R, Adam L, et al. Prognostic implications of $p 53$ protein, epidermal growth factor receptor, and $\mathrm{Ki}-67$ labelling in brain tumors. Br J Cancer 1992; 66: 373-385.

18. Dorward NL, Hawkins RA, Whittle IR. Epidermal growth factor receptor activity and clinical outcome in glioblastoma and meningioma. Br J Neurosurg 1993; 7: 197-199.

19. Pigott TJ, Robson DK, Palmer J, Ward LM. Expression of epidermal growth factor receptor in human glioblastoma multiforme. Br J Neurosurg 1993; 7: 261-265.

20. Fine HA, Dear KBG, Loeffler JS, et al. Meta-analysis of radiation therapy with and without adjuvant chemotherapy for malignant gliomas in adults. Cancer 1993; 71: 2585-2597.

21. Walker MD, Green SB, Byar DP, et al. Randomized comparisons of radiotherapy and nitrosoureas for the treatment of malignant glioma after surgery. N Engl J Med 1980; 303: 1323. 1329.

22. Archibald YM, Lunn D, Ruttan LA, et al. Cognitive functioning in long-term survivors of high grade glioma. J Neurosurg 1994; 80 247-253.

23. Salford L, Brun A, Nirfalk S. Ten-year survival among patients with supratentorial astrocytomas grade III and IV. J Neurosurg 1988; 69: 506-509.

24. Cairncross JG, MacDonald DR, Ludwin S, et al. Chemotherapy for anaplastic oligodendroglioma. J Clin Oncol 1994; 12: 2013 . 2021 . 